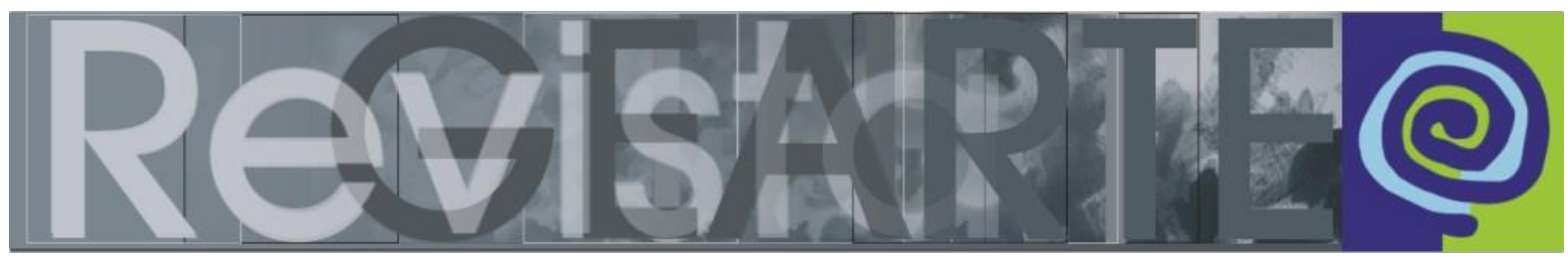

ISSN 2357-9854

\title{
O corpo nas artes e a arte do(s) corpo(s): um caminho (inter) artes para a ecologia de saberes
}

A inspiração para a proposição deste dossiê nasceu do encontro acadêmico, artístico e afetivo de três passantes em território estrangeiro, acontecido, em 2015, em Bogotá, na Colômbia, durante o II Encuentro Latinoamericano de Investigadores/as sobre Cuerpos y Corporalidades en las Culturas. A acolhedora e exuberante Bogotá foi nosso ponto geográfico de confluência, onde experimentamos uma intensa imersão cultural atravessada pela vivência e convivência promovida pelo evento nas conferências, nas comunicações, mas, principalmente, na experimentação das performances em seus múltiplos desvelamentos do corpo e de suas potencialidades. Experiências que aguçaram nossa consciência de ser, de estar, de viver e de conviver naqueles dias, corpos e espaços. Imergimos então efetivamente na reflexão que norteava o evento, anunciada em sua convocatória:

\begin{abstract}
En la búsqueda de comprensiones más equilibradas sobre lo que implica vivir la vida y compartir el mundo de la vida en la complejidad de las actuales circunstancias históricas, políticas y ambientales, la condición corporal de la existencia constituye hoy por hoy uno de los temas obligados y más indagados tanto en los ámbitos investigativos de las ciencias, las artes y las culturas, como en los agenciamientos cotidianos que llevan a cabo las gentes a través de las dinámicas locales, colectivas y periféricas de producción de conocimientos otros (ENCUENTRO LATINOAMERICANO DE INVESTIGADORES/AS SOBRE CUERPOS Y CORPORALIDADES EN LAS CULTURAS, 2015) ${ }^{1}$
\end{abstract}

Perspectiva que tem consonância com as reflexões teóricas de David Le Breton (2006, p. 7) que afirma ser a existência, "antes de qualquer coisa", corporal. O corpo é

[...] o eixo da relação com o mundo, o lugar e o tempo nos quais a existência toma forma através da fisionomia singular de um ator. Através do corpo, o homem apropria-se dos elementos da vida e os traduz para os outros, servindo-se dos sistemas simbólicos que compartilha com o coletivo (BRETON, 2006, p. 7).

1 Informações disponíveis em: <http://red.antropologiadelcuerpo.com/index.php/2do-encuentrolatinoamericano/>. Acesso em: 27 abr. 2017. 
Motivados por esta perspectiva, que foi responsável por nosso encontro, bem como pelo desejo de materializar o vínculo estabelecido entre nós, pensamos e propusemos a elaboração deste dossiê, norteado pela confluência de nossos interesses intelectuais e artísticos em relação às discussões acerca do corpo e de suas representações na e pelas artes e da repercussão desta reflexão na área da educação.

Pensar o corpo como objeto de estudo é propor antes de mais uma reflexão, não somente a partir de suas diferentes acepções, mas, sobretudo, a partir das diversas disciplinas de pesquisa. Inserido em diversos contextos históricos, políticos, culturais e sociais, o corpo como objeto de estudos apresenta um campo vasto e inesgotável campo para estudos interdisciplinares. No âmbito das artes, e, sobretudo, da arte contemporânea, o corpo continua sendo objeto de estudo para pesquisas tanto teóricas, práticas, quanto prático-teóricas. Nesta articulação, artistas, pesquisadores, professores, mas também críticos de arte, curadores, galeristas e instituições culturais desenvolvem e propõe não somente práticas artísticas experimentais, diferentes pontos de vista sobre a representação do corpo e a construção de novas problemáticas do contemporâneo, apresentando o corpo e suas corporalidades a partir de seus aspectos, dos mais materiais aos mais virtuais.

No ambiente de ensino-aprendizagem contemporâneo encontramos diversas procuras de como (inter)relacionar(nos) com os diversos ambientes, conteúdos e com a complexidade da vida e dos saberes; sendo que na intensidade das trocas das experiências e no fluxo das mu(danças) e nos olhares sobre os trajetos das (inter)artes e da Performances como vias de contágio na-com Escola que potencializa os diversos pontos de vista e de abordagem da vida, que podem potencializar as ecologias do saber, instigando a uma revisão constante do ensino.

A proposição de nosso dossiê foi norteada pelo pensamento de Fritjof Capra, que salienta serem todos os fenómenos de nosso cotidiano (inter)conectados em rede, questão esta presente em todo o que o ser humano faz e que expande conceitos e conceptos fossilizados, sendo estas conexões que possibilitam mobilidade do pensamento-ser-soma da unidade ao plural em continum nos seus constantes ires e devires. O enfoque e o recorte temático de nossa proposição nos aproximaram ao 
escopo da Revista GEARTE, que acolheu e confiou em nossa proposta. E foi com grande satisfação que recebemos a resposta positiva de pesquisadores e artistas nacionais e estrangeiros à nossa convocatória, confiando a nós suas pesquisas e seus textos.

Sob a perspectiva de nossa convocatória, alicerçada na ideia de uma Ecologia dos saberes, agrupamos os artigos em três Ecossistemas, que revelam a confluência dos textos, ao mesmo tempo em que estabelecem a sinergia entre estes trabalhos.

Os três primeiros artigos do dossiê: "O corpo na criação efêmera: qual corpo em exposição?", de Cíntia Tosta; "Atitude de Arte, Arte da Atitude: O Dandismo Performático de Gilbert \& George", de Angélica Oliveira Adverse; e "Anacronismo, corpo e memória nas imagens escatológicas de Francisco Toledo", de Vanessa Daniele de Moraes; compõem o que reconhecemos como um Ecossistema dos Corpos/Corporeidades e $(\mathrm{m})$ Arte, uma vez que estão diretamente interessados nas relações estreitas entre corpo/corporeidades e arte.

Em “O corpo na criação efêmera: qual corpo em exposição?”, a performer Cíntia Tosta propõe uma reflexão sobre o corpo na arte a partir da criação efêmera articulada à sua exposição como método. A proposta da autora é compreender e definir o corpo do performer por meio da análise de distintas criações, articulando o artista, a obra no contexto de sua exposição atual e o público. E apresenta, então, uma proposta de método de leitura crítico-ativo da criação efêmera propondo a reflexão sobre o corpo na sua qualidade de: corpo-fronteira, ausência e presença, corpo post-performance, mas também inserido no contexto do virtual.

A performance na relação que estabelece entre o artista e o corpo é, também, a temática de "Atitude de Arte, Arte da Atitude: O Dandismo Performático de Gilbert \& George”, de Angélica Oliveira Adverse, estabelecendo uma relação entre o processo de subjetivação do Dandismo e as performances Gilbert \& George. A hipótese da autora e de que as práticas e a rigorosa disciplina do cultivo do si do Dandismo contribuem para a reinvenção do corpo-artístico como obra de arte e para o processo de "des-dramatização", que reorganizar os padrões perceptivos da cena e a relação do artista com o seu próprio corpo. 
Já "Anacronismo, corpo e memória nas imagens escatológicas de Francisco Toledo", de Vanessa Daniele de Moraes, traz como objeto de análise a obra do artista mexicano Francisco Toledo (1940), que segundo a autora, está duplamente alicerçada no corpo: ao utilizar o excremento (dejeto corporal) como tema e ao, literalmente, formar suas imagens no corpo humano. Como aporte teórico a autora recorre às reflexões de Georges Vigarello e Mikhail Bakhtin acerca da relação entre os fluídos corporais e a sensação de nojo e de repugnância que despertam nas pessoas.

Os três artigos seguintes: "Práticas e técnicas corporais promovendo a presença de artistas com deficiência na cena contemporânea", de Marcia Berselli; "O corpo que joga, ginga e dança: a Capoeira Angola na arte-educação", de Judivânia Maria Nunes Rodrigues; "Corpo(i)ética: arte, corpo e produção de sentidos na educação de jovens e adultos (EJA)", de Fernando Yonezawa e Márcia Cuevas, compõe o Ecossistema dos Corpos/Corporeidades em-com Arte/Saúde \& na Educação/Vida.

Em "Práticas e técnicas corporais, promovendo a presença de artistas com deficiência na cena contemporânea", Marcia Berselli apresenta uma reflexão sobre práticas e técnicas corporais somáticas, que podem se fazer presentes em processos criativos, promovendo assim a presença de artistas com deficiência na cena. Segundo a autora, as práticas corporais de acessibilidade em uma perspectiva atitudinal, podem ser reconhecidas pelos modos flexíveis de abordagens do movimento, mas, sobretudo, pela proposição de interação que mobiliza dinâmicas de privilégio e poder.

"O corpo que joga, ginga e dança: a Capoeira Angola na arte-educação", de Judivânia Maria Nunes Rodrigues, apresenta o trabalho arte-educação realizado pela pesquisadora na Comunidade do Monte Serrat, em Florianópolis-SC. O artigo reflete sobre a investigação da autora em relação a seu próprio fazer como arte-educadora que utilização da Capoeira de Angola como ferramenta para o ensino e a aprendizagem através do corpo. Trabalho que é registrado pela autora por meio de fotografias que expressam a interação e mediação a partir da experiência, no que ela denominou de "Retratos de Movimentos". 
Sob a mesma perspectiva "Corpo(i)ética: arte, corpo e produção de sentidos na educação de jovens e adultos (EJA)", de Fernando Yonezawa e Márcia Cuevas, apresenta a experiência das oficinas corporais-artísticas realizadas pelos autores junto a uma escola municipal de EJA de Vitória (ES). Conforme os autores, o objetivo destas oficinas é produzir uma aprendizagem que ecoe no campo afetivo dos estudantes, buscando para tanto embasamento em conceitos e reflexões de Gilles Deleuze e de Félix Guattari, que acentuam o caráter político, ético e estético destas intervenções.

O terceiro conjunto de artigos: "Breves notas sobre o corpo: um diálogo com Gonçalo M. Tavares e Os Espacialistas”, de Maria Elisa Rodrigues Moreira; "El cuerpo joven como mito una propuesta de antropología narrativa”, de Otto Rosales Cárdenas e Stiver Machado Ramírez; e "Corpo que paira, corpo que flui: corporeidades múltiplas na arte-vivência", de Rosália Menezes e Jo A-Mi compõem o Ecossistema dos (Inter/Trans/Des) Entendimentos sobre-com Corpo/Corporeidades, uma vez que tais artigos propõem diversificadas reflexões sobre o corpo e corporeidade.

"Breves notas sobre o corpo: um diálogo com Gonçalo M. Tavares e Os Espacialistas", de Maria Elisa Rodrigues Moreira, analisa a obra Atlas do Corpo e da Imaginação (20013), do escritor português Gonçalo M. Tavares, em seu dialoga com as imagens produzidas pelo coletivo de artistas-arquitetos Os Espacialistas. Conforme a autora, enquanto o texto de Tavares aborda o corpo a partir de sua presença no método, no mundo, no próprio corpo e na imaginação, as imagens do coletivo (e alguns de seus textos) desestabilizam esses eixos e provocam o leitor a pensar nas possibilidades e maneiras que os corpos têm de situar-se no mundo.

O artigo "El cuerpo joven como mito una propuesta de antropología narrativa", de Otto Rosales Cárdenas e Stiver Machado Ramírez, propõe uma reflexão sobre o corpo jovem enquanto mito na cultura juvenil da década de 1960, abordando três dimensões: o cinema, a moda e a sonoridade. Para tanto, os autores propõem uma exploração antropológica narrativa desta categoria em dois filmes emblemáticos: West Side Story (1961), de Robert Wise, e Sympathy For The Devil (1968), de Jean Luc Godard. 
"Corpo que paira, corpo que flui: corporeidades múltiplas na arte-vivência", de Rosália Menezes e Jo A-Mi, parte da perspectiva do corpo na filosofia ocidental clássica, buscando aporte nos estudos sociológicos e históricos, para realizar uma reflexão crítica sobre a corporeidade, ou seja, sobre o corpo e seus agenciamentos com o mundo. As autoras identificam a experiência artístico-pedagógica da artevivência como viés estratégico de territorialidade crítica enquanto "linha de fuga" que reconstruiu conceitos, percepções e ações sobre o corpo cena-em-si.

O último artigo que apresentamos "La Formación Categorial y la importancia del Arte en ella", de Paola Silvana Vázquez Neira, orbita entre os Ecossistemas elencados por nós para este dossiê, uma vez que perpassa as discussões apresentadas nos artigos anteriores, ao propor uma reflexão sobre relação entre formação e arte. Neste artigo, a autora analisa e discute o papel e a importância das ações pedagógicas, principalmente, no âmbito da arte educação nos processos de formação, destacando que formar significa fazer ou criar, bem como fazer parte de um todo e, ao mesmo tempo, é sinônimo de preparação. Para a autora, cabe à arte educação atuar como autora da capacidade entre sua experiência e identidade individual e coletiva, com os fenômenos e significados da cultura.

Tratando aqui do corpo nas artes e da arte do(s) corpo(s), encerramos este dossiê com o ensaio visual Café com ZMário, do artista José Mário Peixoto Santos (ZMário), que apresenta imagens da performance de mesmo nome realizada por ele, na qual utiliza a cafeteira, o fogareiro portátil, as xícaras diversificadas e coloridas e, principalmente, o café como meios e objetos estéticos para a produção de uma obra entre a arte e a vida, que, em confluência com a culinária performática e relacional de Rirkrit Tiravanija, é pretexto para a criação do encontro e do relato oral sobre vidas, profissões, amores, desejos, frustrações... Fechamos assim a circularidade deste dossiê que se anunciou em potência em um encontro fortuito, acontecido em 2015, com imagens artísticas que tem com temática, justamente, o encontro e suas interações. Para além de materializar a relação de amizade intelectual de seus proponentes, este dossiê faz nascer uma nova rede de entrelaçamentos teóricocríticos e artísticos, que anuncia possíveis e, por vezes, inesperadas reconfigurações. 
Muito felizes com o resultado recebido por nossa convocatória, garrafa jogada no mar infinito de informações e de possibilidades da contemporaneidade, desejamos a todos uma boa e prazerosa leitura.

Dra. Rosângela Fachel de Medeiros²

(Universidade Regional Integrada do Alto Uruguai e das Missões - URI, Frederico Westphalen/ RS, Brasil)

Dr. Leonardo Jose Sebiane Serrano ${ }^{3}$

(Instituto de Humanidades, Artes e Ciências Professor Milton Santos - IHAC - e Universidade Federal da Bahia — UFBA, Salvador/BA, Brasil)

Me.Cíntia Tosta ${ }^{4}$

(Université Paris 8 Vincennes - Saint-Denis, France)

Organizadora/es do presente número

\section{Referências}

II Encuentro Latinoamericano de Investigadores/as sobre Cuerpos y Corporalidades en las Culturas. Disponível em: <http://red.antropologiadelcuerpo.com/index.php/2do-encuentro-latinoamericano/>. Acesso em: 27 abr. 2017.

LE BRETON, D. A sociologia do corpo. Petrópolis/Rio de Janeiro: Vozes, 2006.

2 Professora do Curso de Letras e do Mestrado em Letras da Universidade Regional Integrada do Alto Uruguai e das Missões (URI/FW), integrante da Red Iberoamerica de Investigación en Narrativas Audiovisuales. Email: rosangelafachel@gmail.com

3 Professor Adjunto do Instituto de Humanidades, Artes e Ciências, Professor Milton Santos (IHAC), assim como do Programa de Mestrado Profissional em Artes (ProfArtes) e do Programa de Pósgraduação em Artes Cênicas (PPGAC) da Universidade Federal da Bahia (UFBA). Email: leosebiani@gmail.com

4 Artista plástica e performer formada pela Escola de Belas Artes (EBA), Universidade Federal da Bahia (UFBA), Brasil. Doutoranda em Estética, prática e historia das artes, Escola doutoral EDESTA/laboratório de pesquisa Artes das imagens e arte contemporânea (Ai-AC), Université Paris 8, França. Email: ctztbeauxarts@hotmail.com 